\title{
Cold Active Lipases Produced by Cryptococcus sp. Y-32 and Rhodococcus erythropolis N149 Isolated from Nella Lake, Antarctica
}

\author{
Abhas Kumar Maharana* and Shiv Mohan Singh \\ Polar Biology Laboratory, National Centre for Antarctic and Ocean Research, \\ Vasco-da Gama, Goa-403804, India \\ *Corresponding author
}

\section{Keywords}

Cold active,

Larsemann Hills,

Lipase,

Psychrotolerant,

Sediment core

Article Info

Accepted:

16 February 2018

Available Online:

10 March 2018

\section{A B S T R A C T}

Cold active lipase was investigated by bacteria and yeast isolates from the core sample of Nella Lake, Larsemann Hills region, East Antarctica. Among potential yeasts and bacteria producing lipases, best isolates were identified as Cryptococcus sp. Y-32 and Rhodococcus erythropolis $\mathrm{N} 149$ by molecular technique. In order to enhance the lipase production capabilities, both the isolate again subjected for optimization processes using various physiological (temperature and $\mathrm{pH}$ ) and chemical (Carbon, nitrogen, minerals and various substrates like oils and triglycerides) parameters. The results indicated that a supplement of $1 \% \mathrm{w} / \mathrm{v}$ fructose, $0.1 \% \mathrm{w} / \mathrm{v} \mathrm{KCl}$ and $2 \% \mathrm{v} / \mathrm{v}$ tween 80 at $\mathrm{pH} 8.5$ and $15^{\circ} \mathrm{C}$ enhances the lipase production by 9.81 -fold $(6.81 \mathrm{U} / \mathrm{ml})$ using Rhodococcus erythropolis $\mathrm{N} 149$. In other hands, the activators are $1 \% \mathrm{w} / \mathrm{v}$ of galactose and peptone, $0.1 \% \mathrm{w} / \mathrm{v} \mathrm{KCl}$ and $2.5 \% \mathrm{v} / \mathrm{v}$ ghee at $\mathrm{pH} 11.5$ and $15^{\circ} \mathrm{C}$ enhances the lipase production by 4.01 -fold $(3.35 \mathrm{U} / \mathrm{ml})$ using Cryptococcus sp. Y-32. The present study successfully produced cold-active lipases with novel properties like low temperature and high $\mathrm{pH}$ stability, which can be used in the degradation of lipid wastes in cold regions and also can be used for detergent formulation for cold temperature washing of delicate clothes.

\section{Introduction}

Microorganisms are ubiquitous. Even in extreme environment they can grow and reproduce. Microorganisms loving cold temperature are regarded as psychrophiles having maximum growth temperature $\leq 20^{\circ} \mathrm{C}$ whereas another group is present as facultative psychrophiles or psychrotolerants having maximum growth temperature in the mesophilic range in spite can grow at near to zero temperature (Moyer and Morita, 2007). The biology of Antarctica is dominated by microorganisms other than animals and plants with a high level of adaptation to withstand extreme conditions (Friedmann, 1993).

Previous reports suggest of getting more psychrotolerants from cold habitats like Antarctica than true obligate psychrophiles (Antony et al., 2016; Hatha et al., 2013; Vaz et al., 2011). Over the last decades the Antarctic examined mainly for the presence of psychrophilic bacteria and archea, and more rarely for fungi (Gunde-Cimerman et al., 2003). The chances of getting psychrophiles 
and psychrotolerants are more obvious at polar environments and also can be found in high mountains, glaciers, deep-sea, and alpine soils (Maharana and Singh, 2018).

Lipases (EC 3.1.1.3, glycerol ester hydrolases) are the hydrolytic enzymes that act on carboxylic ester bonds of triglycerides and give diglycerides, monoglycerides, fatty acids and glycerol as end product. Lipases can be produced from various sources of animals, plants and microorganisms. However, for industrial applications, lipases from microorganisms are more focusing because of higher yield, better adaptability and can be easily manipulated genetically (Hasan et al., 2006). Lipases have immense applications to various industries. Now-days cold active lipases are of more demand than that of neutral one because of their lower energy consumption and prevention of loss of volatile compound (Margesin, 2009). Cold active lipases have application in various processes like bio-remediation, and additives in food industries and detergents and also in biotransformation processes (Joseph et al., 2008).

Pseudomonas is regarded as a remarkable producer for cold active lipase (Maharana and Ray, 2013, 2014a, 2015b; Zeng et al., 2004). Besides, other genera for better lipase production are belonged to the genera of Acinetobacter, Aeromonas, Bacillus, Microbacterium, Moraxella, Psychrobacter, Staphylococcus etc. (Joseph et al., 2008). Yeasts like Rhodotorula, Cryptococcus, Yarrowia lipolytica etc. have maximal potentiality to produce cold active lipases (Singh et al., 2014a, b; Taskin et al., 2016; Maharana and Singh, 2018). Besides, Maharana and Ray (2014c) reported psychrotolerant micro-fungi like Absidia, Alternaria, Aspergillus, Chaetomium, Coccoides, Fusarium, Microsporum, Mucor, Penicillium, and Rhizopus producing cold active lipases.
Microbial growth depends on many physical and chemical factors like temperature, $\mathrm{pH}$, salinity, substrates, carbon and nitrogen sources, minerals and even if some amino acids. Enzyme production is directly proportional to the growth of the microorganisms but in some cases, there is maximum enzyme production in the medium by the microorganisms which are in an inactive form, resulting in lower enzymatic activity (Maharana and Ray, 2015a). This condition achieved due to variations in temperature, $\mathrm{pH}$ and nutrient availability. In addition to this, there are many other molecules that show feedback inhibition of enzyme production. Besides, varied microorganisms showed varied affinity towards substrates employed for the production and have their own mechanism for enzymatic hydrolysis. Therefore, optimization for the production of enzymes is essential for various microorganisms and should be compared for the potent.

The present study focused on the production optimization of cold active lipase by yeast Cryptococcus sp. Y-32 and actino-bacterium Rhodococcus erythropolis N149 isolated from Lake Nella, East Antarctica, which is the first attempt on Nella lake microbial isolates producing cold active lipase as per the best of our knowledge.

\section{Materials and Methods}

\section{Sample collection and isolation of bacteria and yeasts}

Current study was on Lake Nella $\left(76^{\circ} 22^{\prime} \mathrm{S}\right.$, $69^{\circ} 24^{\prime}$ E), an ultra-oligotrophic lake located at an altitude of $15 \mathrm{~m}$ a.s.l. in the Broknes peninsula, Larsemann Hills region, East Antarctica. The lake measures $0.157 \mathrm{~km}^{2}$ in area and has a maximum water depth of $8.2 \mathrm{~m}$. Core samples from Lake Nella were collected and cut off into small pieces from $0.5 \mathrm{~cm}$ to 90 
$\mathrm{cm}$, which were brought back to Polar Biology Lab, NCAOR with polar packs and kept at $20^{\circ} \mathrm{C}$ to investigate further. All core samples were subjected for the isolation of bacteria and yeasts. Samples were serially diluted by $10-$ fold dilution technique and spread over various media viz. Antarctic Biological Medium (ABM), ABM/10, Nutrient Agar (NA), NA/10, Zobell Marine Agar (ZMA), ZMA/10, Potato Dextrose Agar (PDA) and PDA/10.

Plates were incubated for 1-2 weeks at 1, 5, 15 and $22^{\circ} \mathrm{C}$ and cultures after visible were streaked on the same agar plate for further purification done by microscopically (Epifluorescence research microscope, BX51 Olympus, Japan) and purified isolates were stored at $1{ }^{\circ} \mathrm{C}$ (Refrigerated incubator, MIR554-PE, Panasonic). Glycerol stocks were prepared in their respective broth with $20 \%$ glycerol (v/v) and kept at $-20^{\circ} \mathrm{C}$ (Biomedical freezer, MDF-U537D, Sanyo).

\section{Screening and selection of potential lipase} producers at cold temperature

\section{Qualitative assay}

All the purified isolates were subjected for screening of extracellular lipase using tributyrin agar base (Hi-media) having tributyrin oil. Those plates were incubated at various temperatures viz. $4,15,22$ and $35^{\circ} \mathrm{C}$, and zone of clearances were determined by subtracting the culture diameter with whole diameter including zone of clearances.

\section{Quantitative assay}

For quantitative assay submerged fermentation technology was implemented. Initially for inoculum preparation, selected isolates were inoculated separately in respective broth and incubated at $15^{\circ} \mathrm{C}$ for $48 \mathrm{~h}$ at $150 \mathrm{rpm}$ in a shaking incubator (Refrigerated incubator shaker, IS-971RF, Jeio tech, Korea) for agitation. For production of lipase freshly prepared inoculum was used. The production was done by using mineral salt medium $\left(\mathrm{gl}^{-1}\right.$ : yeast extract, $1.0 ; \mathrm{NaCl}, 2.0 ; \mathrm{MgSO}_{4}, 0.4$; $\left(\mathrm{NH}_{4}\right)_{2} \mathrm{SO}_{4}, 0.5 ; \mathrm{K}_{2} \mathrm{HPO}_{4}, 0.3 ; \mathrm{KH}_{2} \mathrm{PO}_{4}, 0.3$; $\mathrm{CaCl}_{2} .2 \mathrm{H}_{2} \mathrm{O}$, 0.1; gum arabic, 2.0; $\mathrm{NaNO}_{3}$, 0.5 ; olive oil, $1 \% \mathrm{v} / \mathrm{v} ; \mathrm{pH} 8.0$ ) as recorded by Lee et al., (2003) with slight modifications. The production medium was incubated at $15^{\circ} \mathrm{C}$ and $150 \mathrm{rpm}$ after addition of $5 \%(\mathrm{v} / \mathrm{v})$ inoculum for $72 \mathrm{~h}$.

About $5 \mathrm{ml}$ medium was taken and extraction was done by centrifugation at 12,000 rpm (Refrigerated table top centrifuge, 5810, Eppendorf, Germany) for $20 \mathrm{~min}$ at $4^{\circ} \mathrm{C}$. The supernatant was regarded as crude lipase enzyme and subjected for lipase assay.

Lipase activity was measured spectrophotometrically (UV-Vis spectrophotometer, Specord S 205, Analytik Jena, AG Germany) using $p$-nitrophenyl palmitate (p-NPP) (Sigma-Aldrich Co.) as substrate and formation of $p$-nitrophenol ( $p$-NP) was measured at $400 \mathrm{~nm}$ (Gupta et al., 2002) with slight modifications noted by Maharana and Ray (2015b). One unit of lipase activity is defined as the amount of enzymes releasing one micromole of $p$-NP per minute per milliliter under assay conditions.

\section{Identification of potential isolates}

Molecular identification of the potential isolates producing cold active lipases were done by using ITS-D1/D2 gene and 16s rRNA gene sequencing based molecular technique. The isolates were outsourced to MTCC, Chandigarh, India for molecular identification. The gene sequence was used to carry out BLAST with the nr-database of GenBank database. The consensus sequence of sample was submitted at BankIt, GenBank, and NCBI for the accession numbers. 


\section{Partial characterization of potential isolates}

The potential isolates were subjected for different biochemical and sugar utilization tests. Besides, for physiological characterization, a loopful of culture was inoculated in flask containing $50 \mathrm{ml}$ of broth and the flask were incubated at 5,15,22 and $35^{\circ} \mathrm{C}$ at $150 \mathrm{rpm}$ in a shaking incubator. About $50 \mathrm{ml}$ of broth with varied $\mathrm{pH}$ values $(3,5,7$, 9 and 11) and $\mathrm{NaCl}$ concentrations $(0,1,5,10$ and $20 \% \mathrm{w} / \mathrm{v}$ ) were tested for the growth of isolates at $15^{\circ} \mathrm{C}$ and $150 \mathrm{rpm}$ in a shaking incubator. In each case, growth was analyzed by spectrophotometer at $600 \mathrm{~nm}$ in the interval of $24 \mathrm{~h}$. Furthermore, potential isolates were screened for other hydrolytic enzymes like protease, amylase and cellulase.

\section{Production optimization strategy for lipase}

Production optimization for lipase was done by "one factor at-a-time" (OFAT) method. Factors investigated were incubation period $(24-120 \mathrm{~h})$, substrate concentrations $(0-15 \%$ $\mathrm{v} / \mathrm{v})$, temperature $\left(5,10,15,25,30\right.$ and $\left.35^{\circ} \mathrm{C}\right)$, inoculum size $(0.1-20 \% \mathrm{v} / \mathrm{v})$, initial $\mathrm{pH}(3.5-$ $12.5)$, nitrogen $(1 \% \mathrm{w} / \mathrm{v}$ : yeast extract, beef extract, peptone, $\mathrm{NaNO}_{3}, \mathrm{KNO}_{3}, \mathrm{KNO}_{2}$, $\mathrm{Ca}\left(\mathrm{NO}_{3}\right)_{2} .4 \mathrm{H}_{2} \mathrm{O}$, (NH4) $)_{2} \mathrm{SO}_{4}$ and $\mathrm{NH}_{4} \mathrm{NO}_{3}$ ) and carbon sources $(1 \% \mathrm{w} / \mathrm{v}$ : glucose, maltose, fructose, lactose, galactose, sucrose, carboxymethyl cellulose (CMC) and xylose), and minerals $\left(0.1 \% \mathrm{w} / \mathrm{v}: \mathrm{NaCl}, \mathrm{KCl}, \mathrm{MgCl}_{2}\right.$, $\mathrm{MnCl}_{2}, \mathrm{CaCl}_{2}, \mathrm{BaCl}_{2}, \mathrm{NH}_{4} \mathrm{Cl}_{2}, \mathrm{HgCl}_{2}$ and $\left.\mathrm{ZnCl}_{2}\right)$ and substrates (5\% v/v: olive, tributyrin, ghee, mustard, sesame, sunflower, coconut oil, palmolein, tween 20 and tween 80). In each experiment, the optimized factor was implemented with the control medium and experiments were done in triplicates.

\section{Statistical analysis}

The data recorded during the investigation were subjected to significance testing by t-test, analyses of variance (ANOVA) and Pearson's correlation coefficient using Microsoft excel 2007. Statistical significance was set at $p<0.05$, and for high significance set at $p<0.001$. Results were denoted as mean \pm standard error of triplicate experiments.

\section{Results and Discussion}

\section{Screening and selection of potential lipase producers}

All the bacterial and yeast isolates were investigated for lipase production by plate assay method. Among them best three from yeasts and five from bacteria were selected for further quantification using two substrates i.e. olive oil and tributyrin at $15^{\circ} \mathrm{C}$ for 5 days. Figure 1 denotes lipase production by potential isolates, where it was found that olive oil was regarded as a good substrate for lipase than tributyrin and maximal lipase were produced by Y-32 (yeast) and N149 (bacteria). ANOVA reveals a highly significant variation $(p<0.001)$ in lipase activity among the yeast and bacterial isolates with respect to olive oil and tributyrin.

\section{Identification and partial characterization of Y-32 and N149}

From molecular identification it was found that Y-32 is identified as Cryptococcus sp. Y32 (GenBank accession no. KY887681) and N149 as Rhodococcus erythropolis N149 (GenBank accession no. KY783363) and phylogenetic tree is represented in Figure 2. Isolate Y-32 showed closest similarity (99.9\%) with Cryptococcus sp. RY-21 (GenBank accession no. AB259936) which was isolated from permafrost, Russia (Fattakhova et al., 2017, Unpublished). The isolate N149 showed closest similarity (99.9\%) with Rhodococcus erythropolis Pi3 (GenBank accession no. AM905947) which was isolated from alkaline ground waters 
contaminated by benzene, toluene, ethylbenzene, xylenes (BTEX) from the SIReN aquifer, UK and had the ability for benzene-degrading (Fahy et al., 2008).

Figure 3 shows the macro- and micromorphology and lipase activity at 4 and $15^{\circ} \mathrm{C}$ by both the isolates. Cryptococcus sp. Y-32 can utilize various sugars as carbon sources viz. D-glucose, raffinose, D-gluconate, Dribose, D-arabinose, lactose, glycerol, DLlactate, myoinositol, D-xylose, maltose, cellobiose, melezitose, D-glucoronate, mannitol, D-galactose, rhamnose and Larabinose. Between nitrogen sources, Y-32 utilizes nitrate, nitrite, lysine, tryptophan and creatinine. Rhodococcus erythropolis N149 is an aerobic, Gram positive rod actinobacterium and was tested for many biochemical analyses. It is positive for catalase and oxidase tests and negative for MRVP, indole, citrate utilization, esculinase and phosphatase tests. Besides, it can utilize various sugars as carbon sources viz. Dxylose, dextrose, D-galactose, melibiose, sucrose, mannose, adonitol, arabitol and malonate. Optimum temperature for the growth of both the isolate is $15^{\circ} \mathrm{C}$, followed by $5^{\circ} \mathrm{C}$ (Fig. 4). It was found that there is almost no growth at $35^{\circ} \mathrm{C}$. It denotes psychrotolerant nature of Cryptococcus sp. Y32 and Rhodococcus erythropolis N149. Both Y-32 and N149 have the ability to tolerate a wide range of $\mathrm{pH}$, i.e. $\mathrm{pH}$ 3-11 and 5-9, respectively. But the optimum was $\mathrm{pH} 11$ and 7 for Y-32 and N149, respectively (Fig. 4). Y32 showed the ability to grow at $10 \% \mathrm{w} / \mathrm{v}$ salt concentrations while N149 hardly showed growth at $10 \%$. But both can grow at $1 / 10^{\text {th }}$ strength of their respective broth medium (Fig. 4). Y-32 is negative for other enzymes like amylase, cellulase and protease while N149 can degrade various substrates apart from tributyrin i.e. skim milk (cold active protease) and carboxymethyl cellulose (cold active cellulase) and negative for amylase.

\section{Effects of production parameters on lipase by N149 and Y-32}

Figure 5 reveals that maximum lipase was produced at $15^{\circ} \mathrm{C}$ by both the isolates and after $25^{\circ} \mathrm{C}$ lipase activity decreased, which confirm that cold temperature is needed for them to produce lipase. ANOVA reveals that there is a highly significant variation $(p<0.001)$ in lipase activity among the isolates. There is a negative correlation between both the isolates with incubation temperatures, which denote with an increase in temperature the lipase activity decreases significantly. Significant test also confirmed by t-test where both the isolate has significant variation along the temperature at 2 -tail $(p<0.05)$.

Inoculum sizes ranging from $0.1-20 \%(\mathrm{v} / \mathrm{v})$ were taken for lipase production. From Figure 6 it was found that there is a variation in inoculum size requirements for lipase production by both the isolates. The optimum inoculum size was $2 \% \mathrm{v} / \mathrm{v}$ and $15 \% \mathrm{v} / \mathrm{v}$ by Cryptococcus sp. Y-32 and Rhodococcus erythropolis $\mathrm{N} 149$, respectively. The t-test reveals a significant variation among the inoculum tested with the respective isolates at $p<0.05$ while there is a positive correlation between the inoculum sizes with that of lipase activity by $\mathrm{N} 149$ significantly $(p<0.01)$. There is a negative correlation between the inoculum sizes with lipase activity by Y-32 significantly at $p<0.001$.

Olive oil ranging from $0-15 \% \mathrm{v} / \mathrm{v}$ was investigated for lipase production at $15^{\circ} \mathrm{C}$. Figure 7 reveals the maximum lipase was produced due to the application of $2.5 \% \mathrm{v} / \mathrm{v}$ and $2 \% \mathrm{v} / \mathrm{v}$ olive oil in the production medium by Cryptococcus sp. Y-32 and Rhodococcus erythropolis $\mathrm{N} 149$, respectively. The t-test reveals that there is a significant variation among the population means of both the isolates with respect to different olive oil concentrations at $p<0.05$. 
Fig. 1 Lipase production by potential isolates at $15^{\circ} \mathrm{C}$. The results are the means of 3 independent experiments and the bars correspond to standard errors

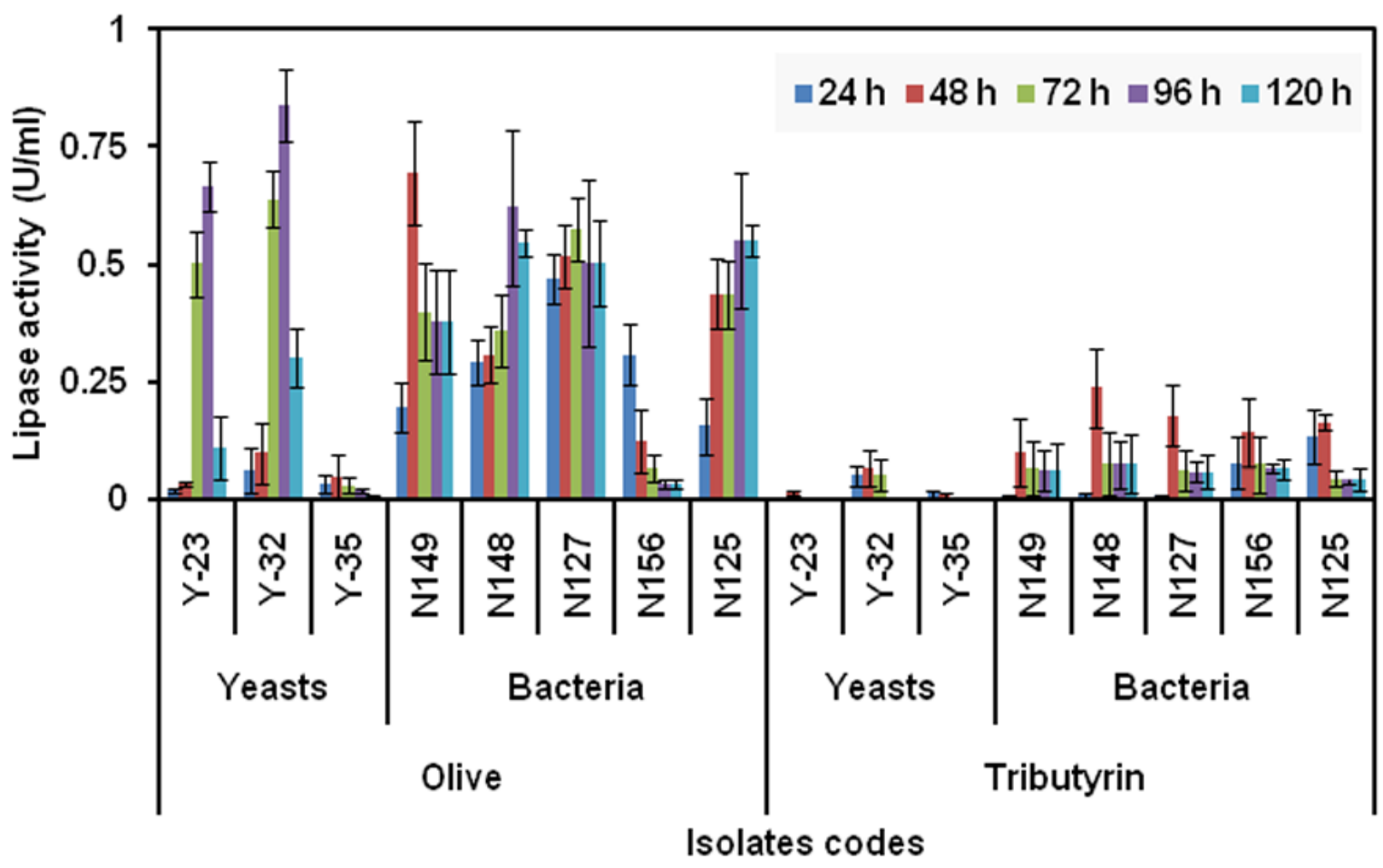

Fig.2 Molecular phylogenetic analysis of A. N149 and B. Y-32. Figure showing the position of current strain in relation to the other genera. GenBank accession numbers for the sequences are shown in parentheses. Numbers at nodes denote bootstrap values based on 1000 replicates.

Evolutionary analyses were conducted in MEGA5
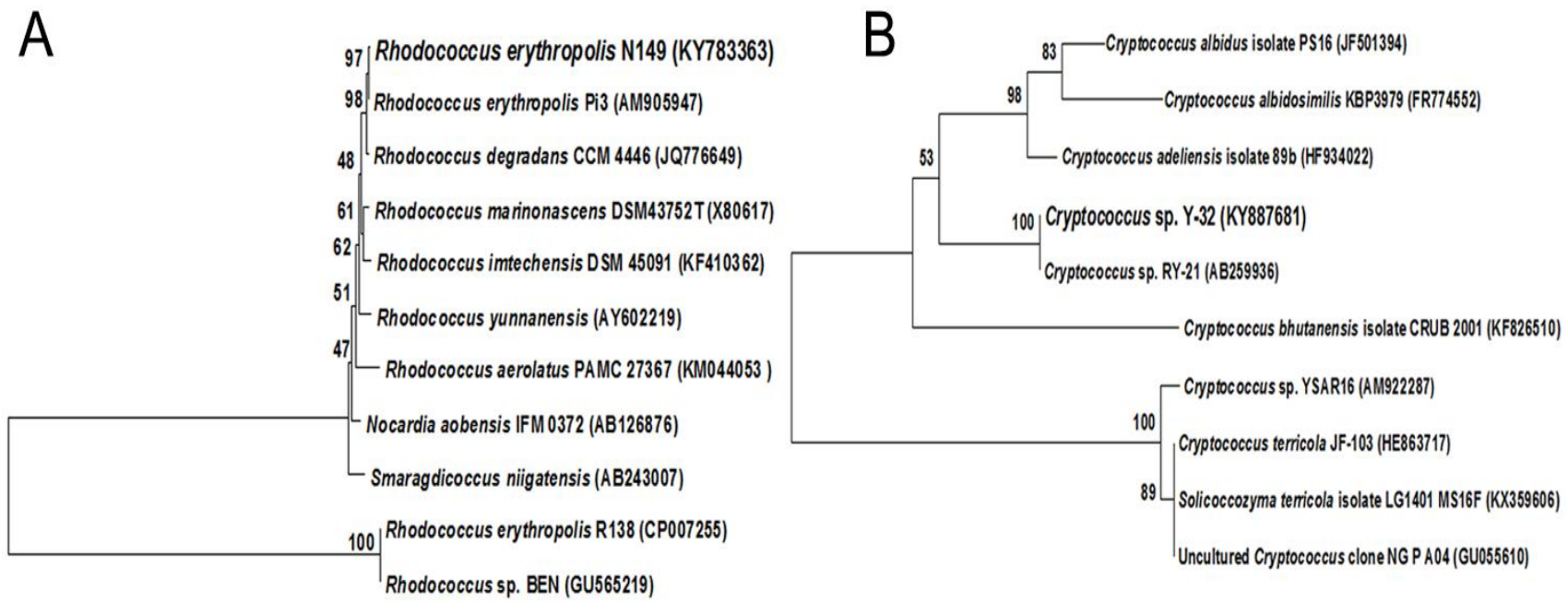
Fig.3 A. N149 on NA, B. micro-morphology of N149 observed under 60X, C. Y-32 on PDA and D. micro-morphology of Y-32 observed under 100X. Lipase plate assay at different temperatures, E. $4^{\circ} \mathrm{C}$ by N149, F. $15^{\circ} \mathrm{C}$ by N149, G. $4^{\circ} \mathrm{C}$ by $\mathrm{Y}-32$ and $\mathrm{H} .15^{\circ} \mathrm{C}$ by $\mathrm{Y}-32$ on tributyrin agar plates
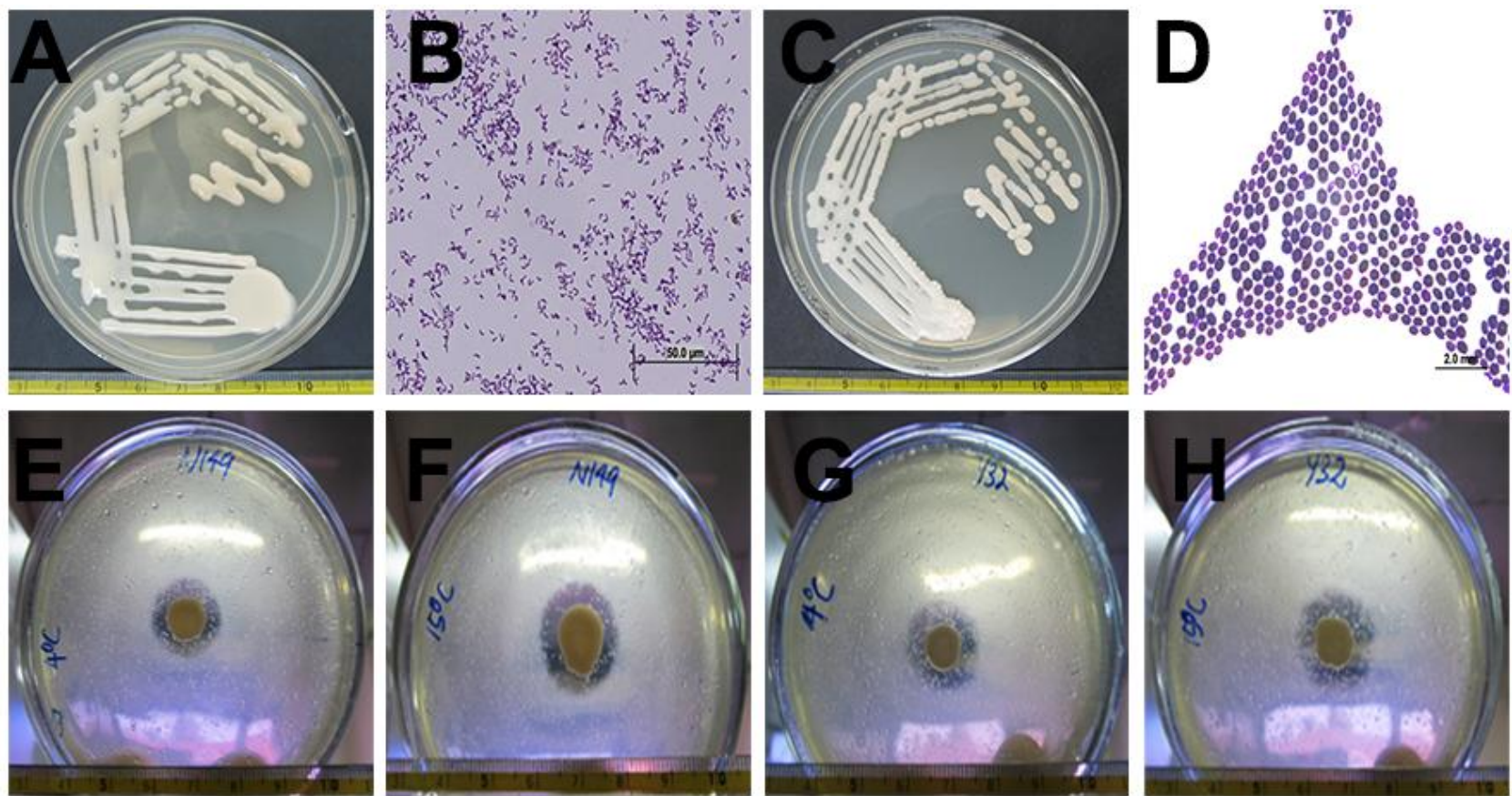

Fig.4 Effects of temperature, $\mathrm{pH}$ and salt concentrations on growth of Y32 and N149. PDB:

Potato dextrose broth

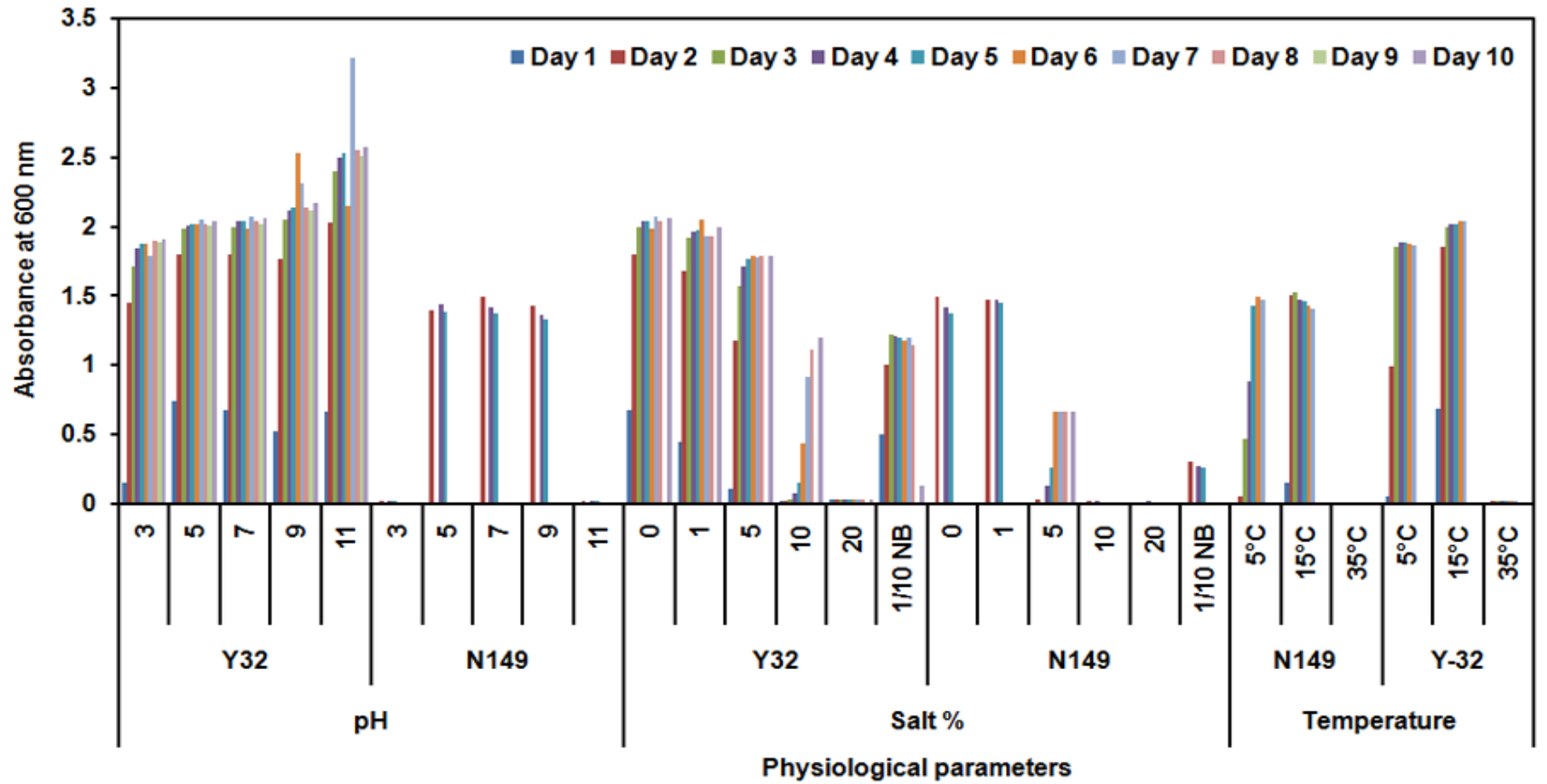


Fig.5 Effects of various temperatures on lipase production by N149 and Y-32. The results are the means of 3 independent experiments and the bars correspond to standard errors

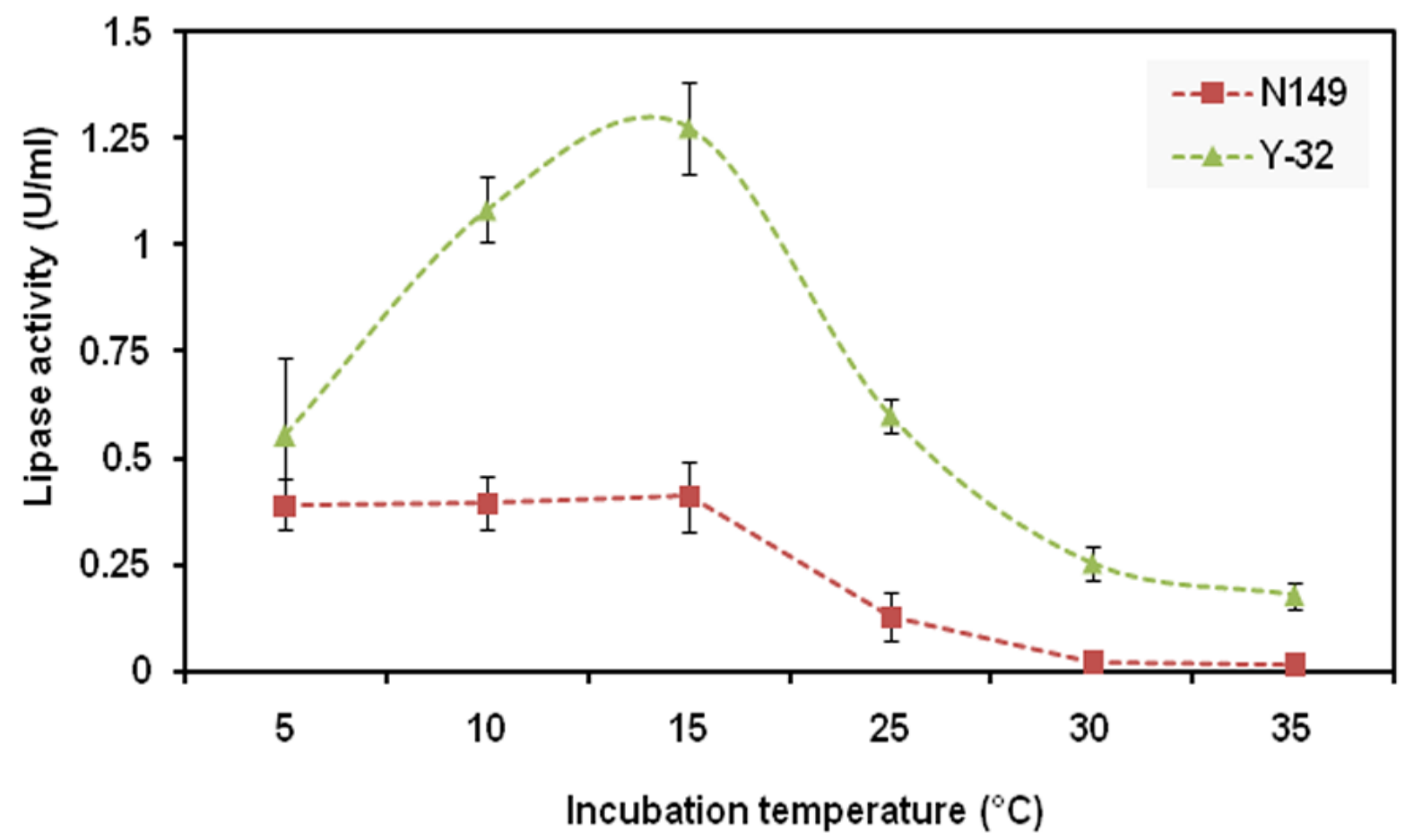

Fig.6 Effects of inoculum size on lipase production by N149 and Y-32. The results are the means of 3 independent experiments and the bars correspond to standard errors

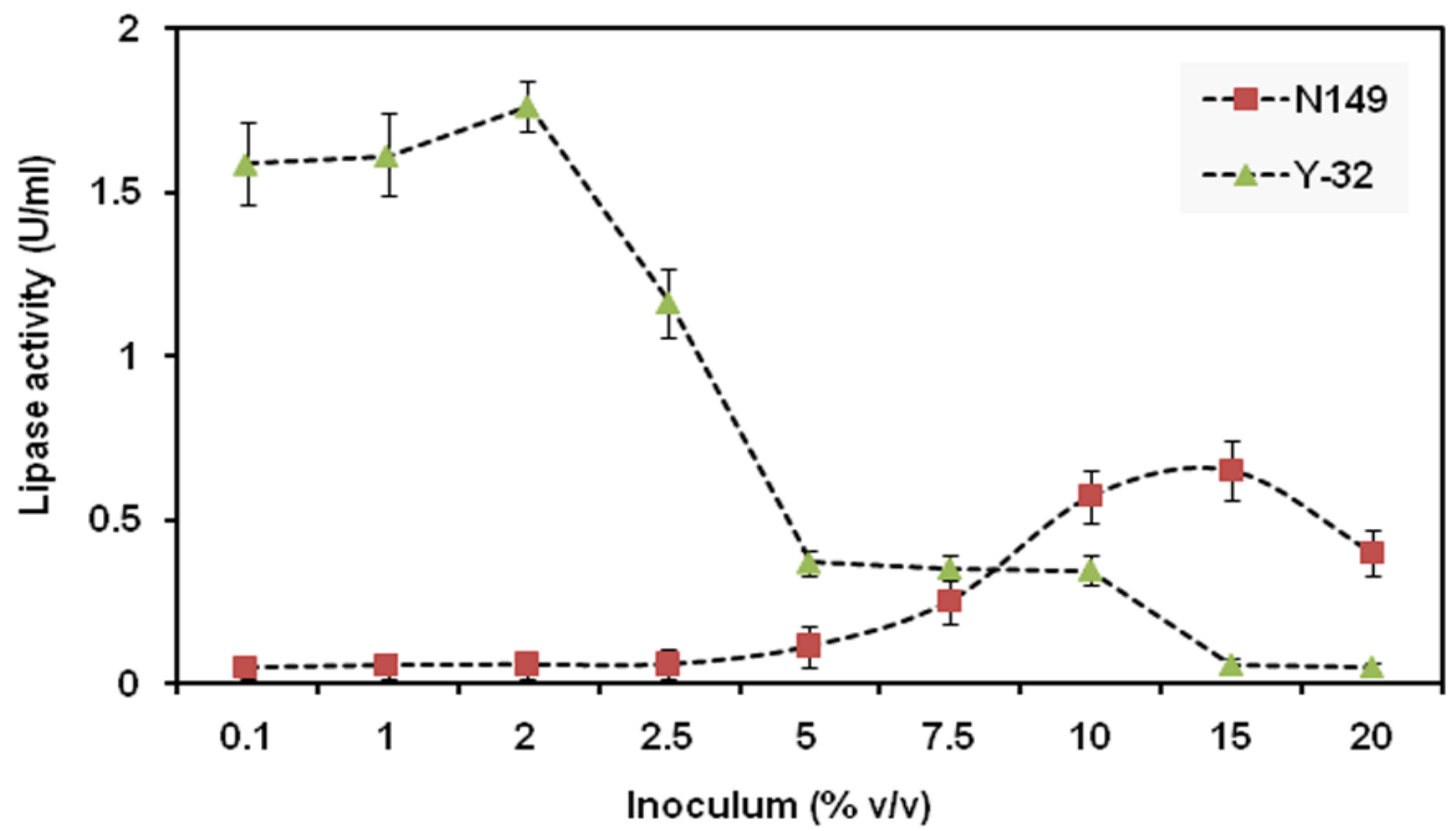


Fig.7 Effects of olive oil concentrations on lipase production by N149 and Y-32. The results are the means of 3 independent experiments and the bars correspond to standard errors

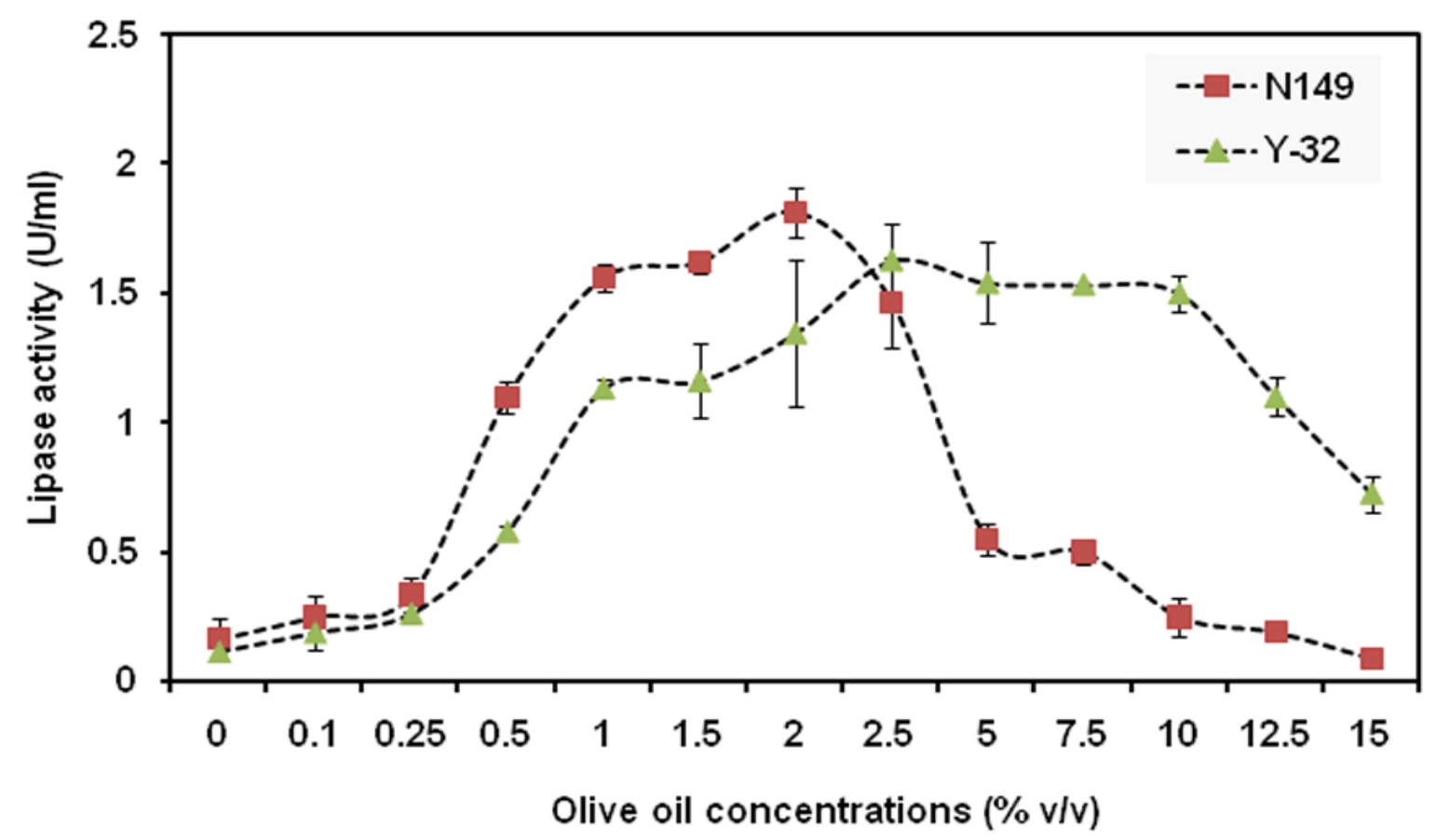

Fig.8 Effects of initial pH on lipase production by N149 and Y-32. The results are the means of 3 independent experiments and the bars correspond to standard errors

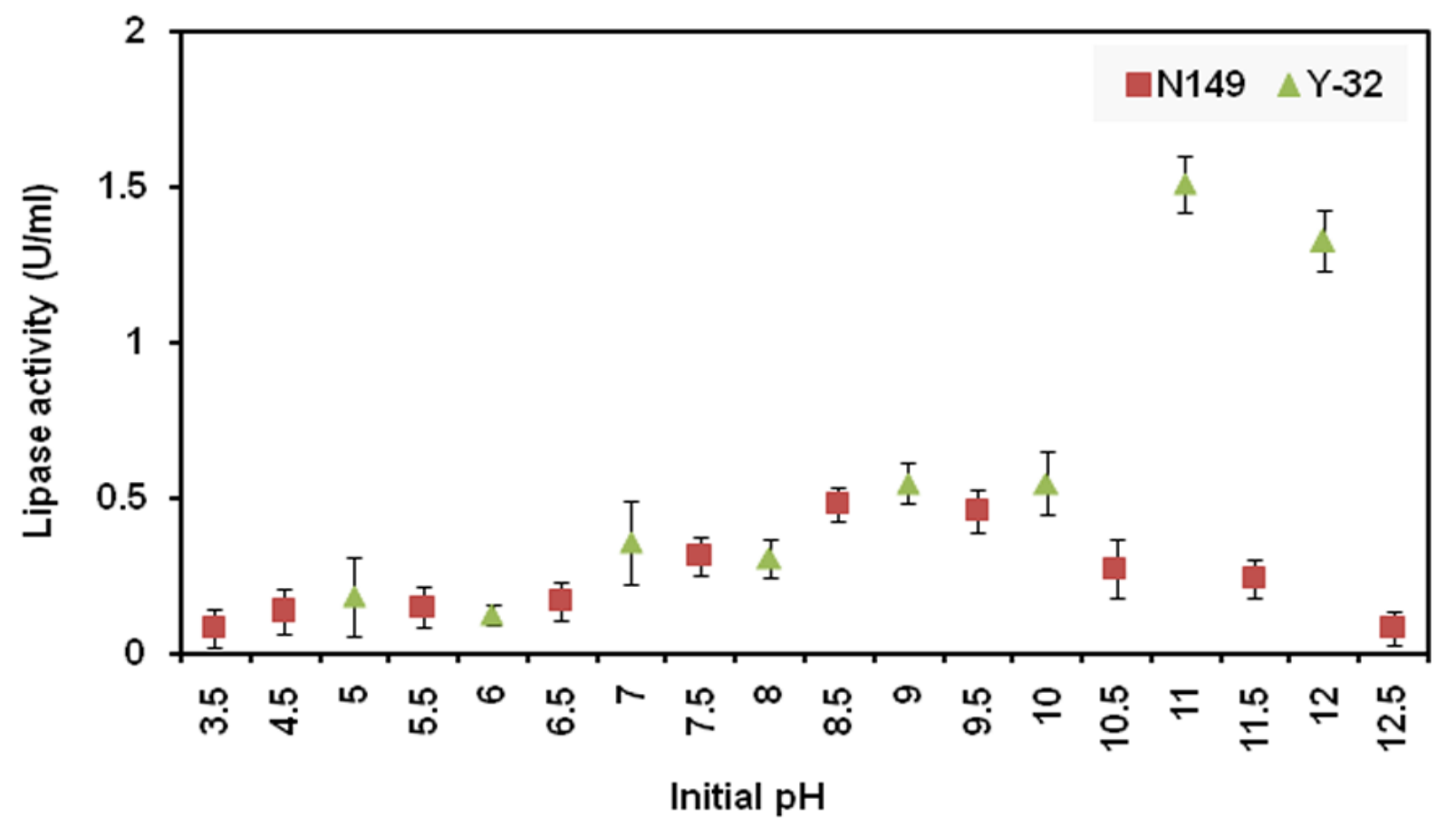


Fig.9 Effects of carbon sources on lipase production by N149 and Y-32. The results are the means of 3 independent experiments and the bars correspond to standard errors

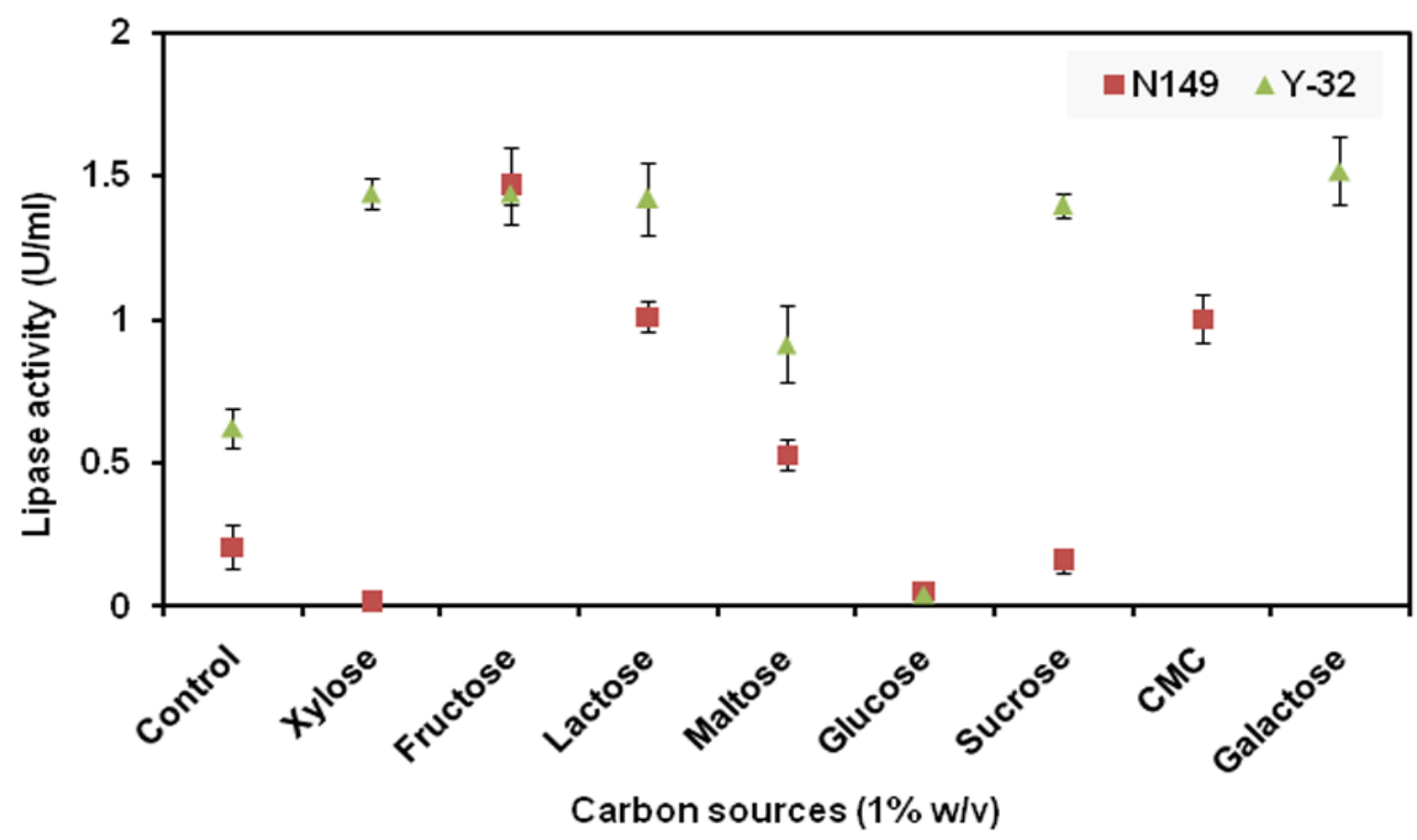

Fig.10 Effects of nitrogen sources on lipase production by N149 and Y-32. The results are the means of 3 independent experiments and the bars correspond to standard errors

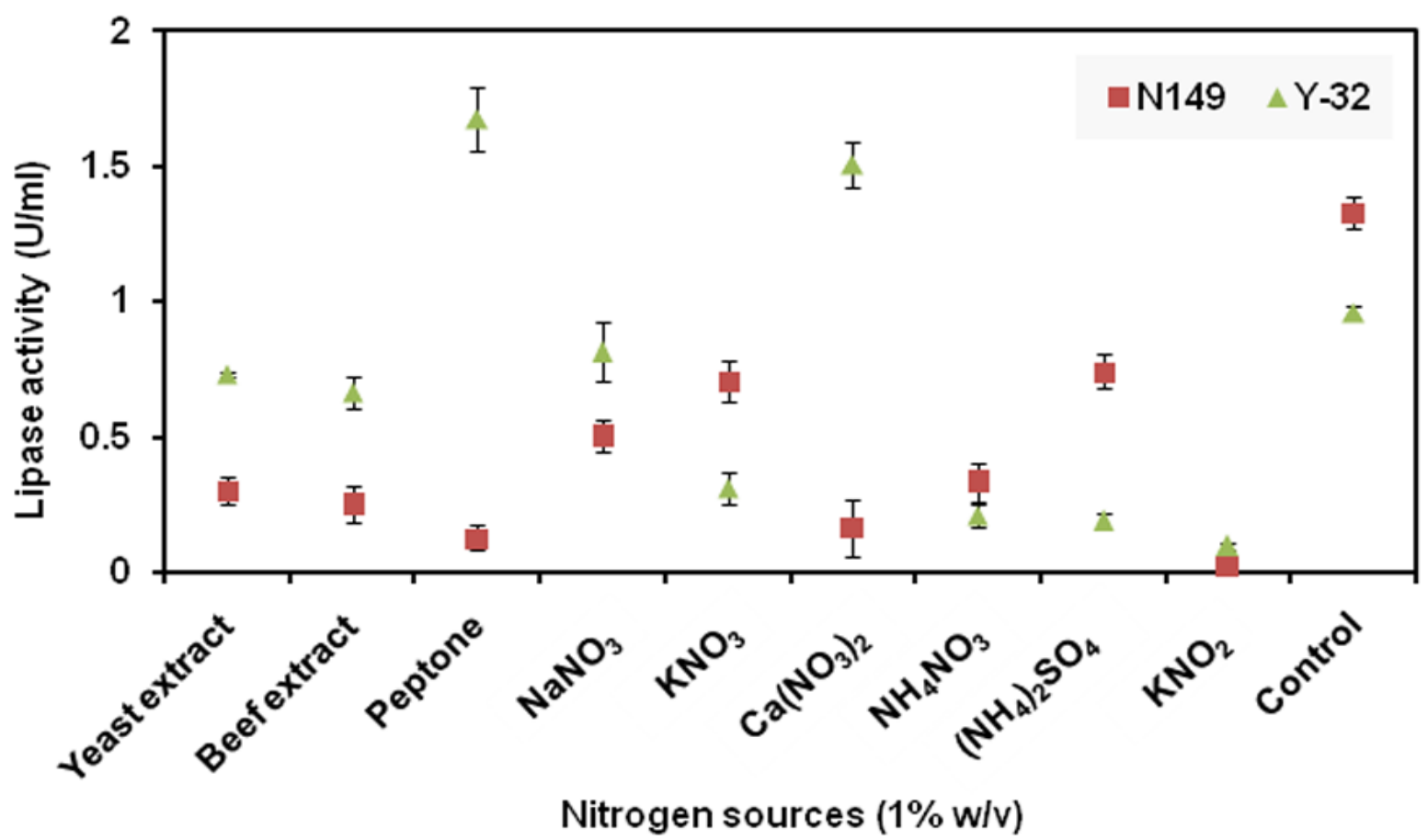


Fig.11 Effects of minerals on lipase production by N149 and Y-32. The results are the means of 3 independent experiments and the bars correspond to standard errors

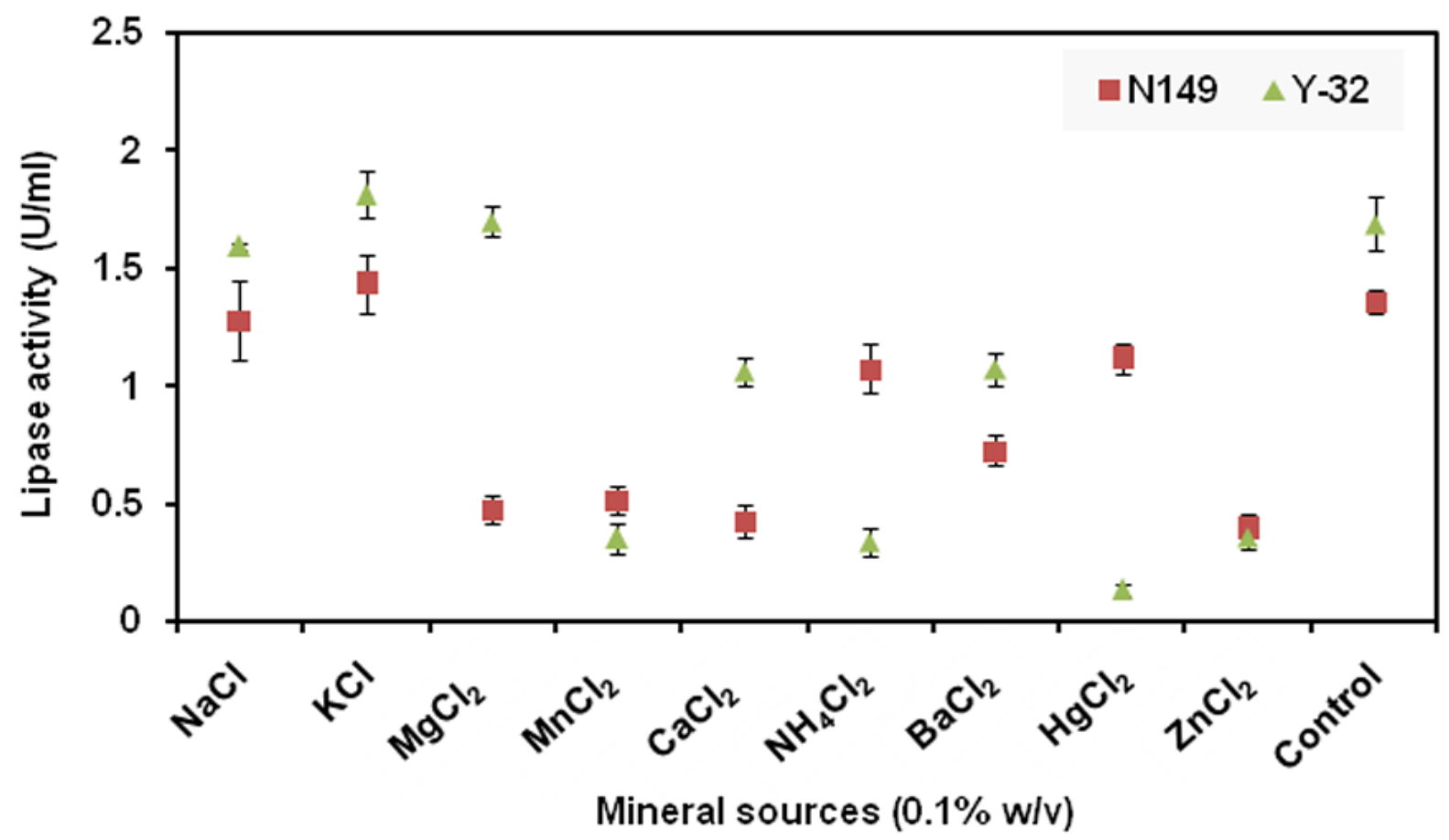

Fig.12 Effects of different substrates on lipase production by N149 and Y-32. The results are the means of 3 independent experiments and the bars correspond to standard errors

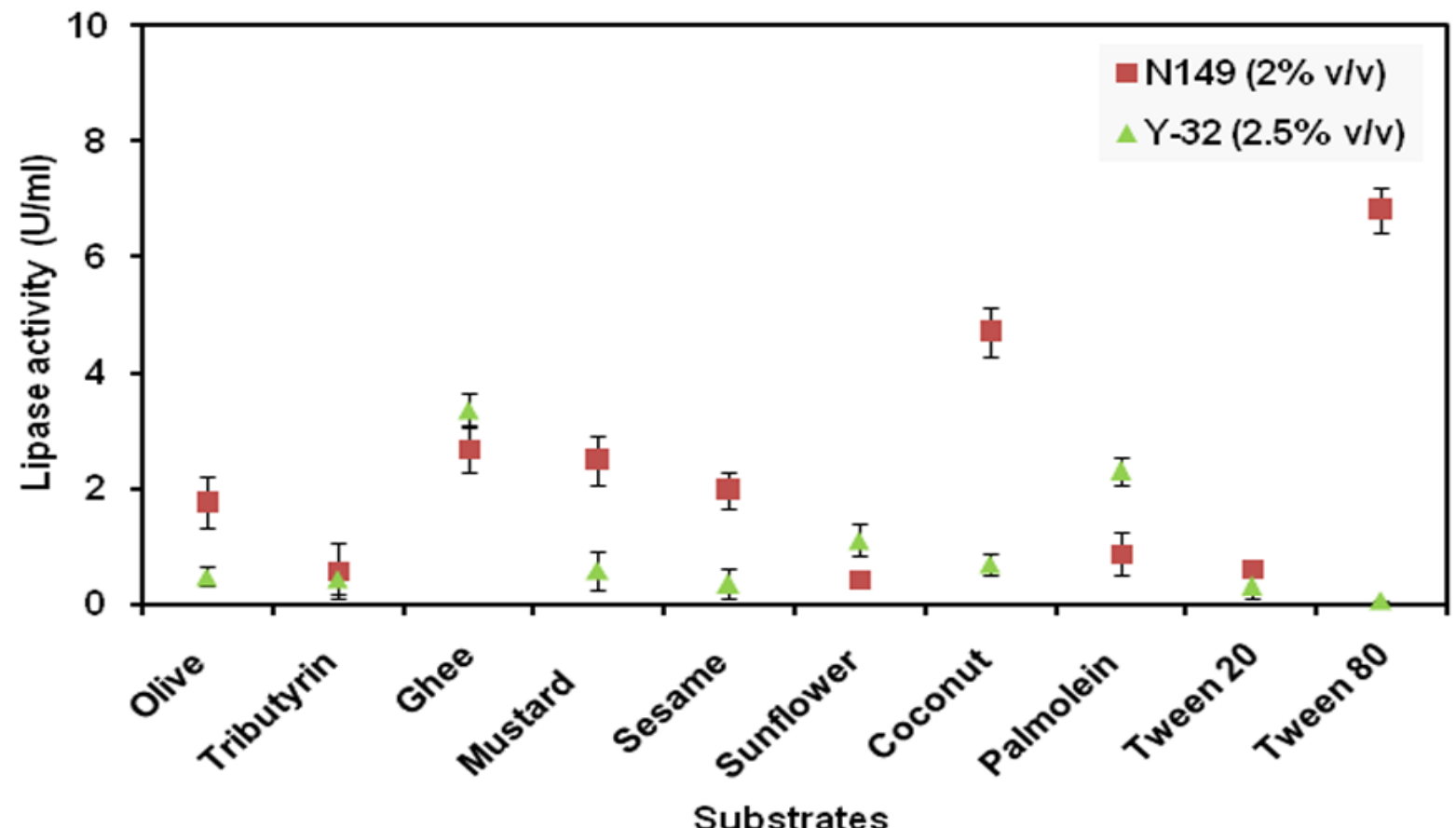


The optimum $\mathrm{pH}$ for lipase production was 11.0 and 8.5 by Cryptococcus sp. Y-32 and Rhodococcus erythropolis N149, respectively (Fig. 8). The t-test reveals that there is a highly significant variation among the population means of both the isolates with respect to different $\mathrm{pH}$ at $p<0.001$. There is a highly significant and positive correlation between the initial $\mathrm{pH}$ with that of lipase activity by Y-32 $(p<0.001)$ denotes with an increase in $\mathrm{pH}$ lipase production increases.

Figure 9-11 show the effects of carbon, nitrogen and mineral sources on lipase production by both the isolates at $15^{\circ} \mathrm{C}$. In case of yeast Y-32 galactose regarded as the most potent inducer among other carbon sources investigated whereas glucose acts as a potent inhibitor. Likewise, N149 showed maximum production with fructose $1 \% \mathrm{w} / \mathrm{v}$ while potential inhibitors were xylose, glucose and sucrose (Fig. 9). Amongst nitrogen sources, potent activator was peptone by Y-32 whereas N149 did not require any additional nitrogen sources while compared with the control which may be due to the presence of yeast extract $0.1 \% \mathrm{w} / \mathrm{v}$ in the initial production medium which was enough for the growth of N149 to produce lipase (Fig. 10). All the minerals except $\mathrm{KCl}$ contributed as the in-activators for lipase production by both Y-32 and N149 while compared with the control (Fig. 11).

Due to specificity nature of the enzymessubstrate reactions lipase was produced by using different types of oils and triglyceride by $\mathrm{Y}-32$ and $\mathrm{N} 149$ at $15^{\circ} \mathrm{C}$. Figure 12 reveals the maximal production was found when media were employed with ghee $(3.35 \mathrm{U} / \mathrm{ml})$ and tween $80(6.81 \mathrm{U} / \mathrm{ml})$ in case of Cryptococcus sp. Y-32 and Rhodococcus erythropolis N149, respectively. The t-test reveals a significant difference between the means of the lipase activity of both the isolates $(p<0.05)$.
Present study emphasizes on lipase production in cold temperature conditions. Therefore, cold temperature isolates were isolated from sediments samples of Nella Lake and screened primarily on tributyrin agar plates and then the potential isolates were selected on the basis of the zone of clearances and submerged fermentation technique. From Figure 1 it was concluded N149 and Y-32 were the potent bacterium and yeast for hyper lipase production respectively. This figure also unfolds the potential substrates among olive and tributyrin. The present study is in contrast with the study of Joseph et al., (2012) who reported that tributyrin induced lipase production by Microbacterium luteolum isolated from Gangotri glacier, western Himalaya. But there is a report of getting Rhodotorula sp. able to produce cold active lipase using olive oil (Rapp and Backhaus, 1992; Divya and Padma, 2015). There are many reports of getting cold active lipase by bacteria and fungi isolated from various regions like Antarctica (Vaz et al., 2011; Carrasco et al., 2012; Antony et al., 2016), Arctic (Hatha et al., 2013; Singh et al., 2012b, 2014a, b, 2015) and other deep sea and temperate regions (Buzzini and Martini, 2002; Jeon et al., 2009; Joseph et al., 2012; Maharana and Ray, 2014a, b, 2015b).

The occurrence of Cryptococcus sp. in the present study is in accordant with that of Cryptococcus yeasts isolated from snow and ice in Antarctica (Buzzini et al., 2012; Zalar and Gunde-Cimerman, 2014). Cold active lipase produced by Cryptococcus spp. (Carrasco et al., 2012; Hatha et al., 2013; Vaz et al., 2011) were also reported from various sources but all of them reported lipase in qualitative method only. There are reports of lipase producing Rhodococcus from cold habitats (De Santi et al., 2014). There is no report of getting cold active lipase from Rhodococcus erythropolis and this is the first 
report of getting the same genus from Nella Lake, Antarctica. However, Rhodococcus spp. was dominant in glacial snow and soil. There are reports of getting Rhodococcus spp. from Pindari glacier (Shivaji et al., 2011), Antarctic sediments (Muangchinda et al., 2014), cold desert of the Himalayas (Mayilraj et al., 2006), and Arctic glacier (Reddy et al., 2009). Pham et al., (2014) reported on the role in bioremediation at cold habitats by Rhodococcus strains. $R$. erythropolis T7-2 was isolated from the oil-contaminated mud of Bohai Sea, northern China, capable of degrading diesel oil at $15^{\circ} \mathrm{C}$ (Huang et al., 2008). Cold-tolerant alkane-degrading Rhodococcus species isolated from near Scott Base, Antarctica (Bej et al., 2000).

Optimization of process parameters is necessary for hyper production of enzymes. Therefore, different physical and chemical parameters investigated. Temperature is an important factor that not only alters the growth of microorganisms but also indirectly controls enzyme production due to thermo labile nature of enzymes. Cryptococcus sp. Y32 produced maximum lipase production as compared with Rhodococcus erythropolis N149 and both have optimum growth temperature of $15^{\circ} \mathrm{C}$. The isolates are psychrotolerant in nature. Therefore, lipase production was maximum at these conditions as lipase production is directly proportional to the growth of the organisms. Cryptococcus spp. isolated from lake sediments of King George Island, the sub-Antarctic region were able to produce lipase more at $4^{\circ} \mathrm{C}$ than $20^{\circ} \mathrm{C}$ (Vaz et al., 2011) but they mentioned only qualitative data for lipase at lower temperature by plate assay method.

Initial inoculum size is also a vital factor that affects the enzyme production. The variation between the present isolates in small and large inoculum size by Y-32 and N149, respectively can be defined in terms of genus variations and initial incubation periods. The exhaustion of nutrients, productions of inhibitors and depletion of oxygen causes less lipase production in larger inoculum size (Abo-State et al., 2010). Singh et al., (2012a) also reported that with the increase in inoculum size enzyme production decreased due to increase in the duration of the initial lag phase.

For optimal production of any enzyme, there is a requirement of suitable substrate in the appropriate amount which not only will be utilized by the concerned microorganism for their growth but also can help to enhance the enzyme production effectively. The present study revealed maximal production using olive oil as compared with tributyrin, which is in accordance with the study of others (Rapp and Backhaus, 1992; Divya and Padma, 2015).

Alkaline range denotes the alkali tolerant nature of both the microorganisms $\mathrm{Y}-32$ and N149. From $\mathrm{pH}$ tolerance study, it was found that the optimum growth $\mathrm{pH}$ for both is 5.0 to 9.0 (Fig. 4). Therefore, maybe there is a chance of getting lipases that tolerate higher $\mathrm{pH}$ efficiently. Inappropriate $\mathrm{pH}$ in the production medium alters the 3-D shape of the protein which in turn reform protein recognition and the enzyme might become inactive. In other senses, $\mathrm{pH}$ also affects the growth of microorganism. The acidic $\mathrm{pH}$ was inhibiting the lipase production which might be due to the fact that microorganism's growth decreased because of acidic medium or the medium became more acidic due to release of more fatty acids to the production medium from olive oil which in turn show feedback inhibition mechanism (Maharana and Ray, 2015b).

For growth, all microorganisms need energy sources. Therefore, different kinds of carbon, nitrogen and mineral sources were employed 
in the production medium for maximal production of lipase. Carbon, nitrogen and mineral sources stimulate lipase production indirectly by giving additional nutrients to the microorganisms for growth which in-turn enhance the enzyme production in same proportion.

Besides, different kinds of oils and triglycerides were investigated to test the affinity of the microorganism for the production of lipase at cold temperatures. From Figure 12 it was found that almost all the oils have induced effect on lipase production besides, Ghee and tween 80 was regarded as the best substrate for lipase production by Y-32 and N149, respectively.

Both the isolate have the ability for the hydrolysis of different vegetable oils investigated, which are industrially and economically important in the production of bio-diesel.

Lipase produced from Cryptococcus sp. S-2 showed maximum activity on $120 \mathrm{~h}$ at $25^{\circ} \mathrm{C}$ with $\mathrm{pH} 5.6$ and have capability to hydrolyze sardine oil, soy bean oil and triolein (Kamini et al., 2000). Huang et al., (2008) investigated on Rhodococcus erythropolis having diesel oil degradation capabilities which was induced by the application of $\left(\mathrm{NH}_{4}\right)_{2} \mathrm{SO}_{4}$ and yeast extract.

In summary, the present study successfully optimized the production medium enhancing the lipase production effectively from unoptimized conditions, which confirmed from the fold increase in lipase by 9.81 using Rhodococcus erythropolis N149 and 4.01-fold using Cryptococcus sp. Y-32. Besides, to the best of our knowledge, our study is the first report on Cryptococcus sp. and Rhodococcus erythropolis isolated from Nella Lake, Antarctica producing cold active lipase. Therefore, lipases produced from above cold tolerant microorganisms can be used in various fields of science like detergent formulation for cold temperature washing of clothes and lipid contaminants removal from waste water in cold and temperate regions due to their alkaline and cold tolerance capabilities. Present studied cold active lipase may provide new insights into the potential biotechnological applications of these isolates in Antarctic environments.

\section{Acknowledgements}

This study was financed by institutional project "Microbial Diversity of Antarctica" at National Centre for Antarctic \& Ocean Research, Vasco-da-Gama, Goa, India. Authors are grateful to the Director, NCAOR, Goa, for facilities and Dr. Alok Kumar Srivastava, Principle Scientist, Plant Pathology, ICAR-NBAIM, Kushmaur, U.P. and Dr. G.S. Prasad, Chief Scientist, Institute of Microbial Technology, Chandigarh for molecular identification of isolates. This research was funded by Ministry of Earth Sciences, National Center for Antarctic and Ocean Research.

\section{References}

Abo-state, M. A. M., M. Swelim, A. I. Hammad and Gannam, R. B. 2010. Some critical factors affecting cellulase(s) production by Aspergillus terreus Mam-F23 and Aspergillus flavus Mam-F35 under solid state fermentation of wheat straw. World Appl. Sci. J. 9(10): 1171-1179.

Antony, R., A. Sanyal, N. Kapse, K. P. Dhakephalkar, M. Thamban and Nair, S. 2016. Microbial communities associated with Antarctic snow pack and their biogeochemical implications. Microbiol. Res. 192, 192-202.

Bej A. K., D. Saul and Aislabie, J. 2000. Coldtolerant alkane-degrading Rhodococcus species from Antarctica. Polar Biol. 23, 100-105. 
Brandão, L.R., D. Libkind, A. B. Vaz, L. C. Espírito Santo, M. Moliné, V. de García, M. van Broock and Rosa, C. A. 2011. Yeasts from an oligotrophic lake in Patagonia (Argentina): diversity, distribution and synthesis of photoprotective compounds and extracellular enzymes. FEMS Microbiol. Ecol. 76(1): 1-13.

Buzzini, P., and Martini, A. 2002. Extracellular enzymatic activity profiles in yeast and yeast- like strains isolated from tropical environments. J. Appl. Microbiol. 93, 1020-1025.

Buzzini, P., E. Branda, M. Goretti and Turchetti, B. 2012. Psychrophilic yeasts from worldwide glacial habitats: diversity, adaptation strategies and biotechnological potential. FEMS Microbiol. Ecol. 82(2): 217-241.

Carrasco, M., J. M. Rozas, S. Barahona, J. Alcaíno, V. Cifuentes and Baeza, M. 2012. Diversity and extracellular enzymatic activities of yeasts isolated from King George Island, the subAntarctic region. BMC Microbiol. 12(1): 251-259.

De García, V., S. Brizzio, D. Libkind, P. Buzzini and Van Broock, M. 2007. Biodiversity of cold-adapted yeasts from glacial melt Water Rivers in Patagonia, Argentina. FEMS Microbiol. Ecol. 59(2): 331-341.

De Santi, C., P. Tedesco, L. Ambrosino, B. Altermark, N. P. Willassen and de Pascale, D. 2014. A new alkaliphilic coldactive esterase from the psychrophilic marine bacterium Rhodococcus sp.: functional and structural studies and biotechnological potential. Appl. Biochem. Biotechnol. 172(6): 3054-3068.

Divya, K., Padma, P. N. 2015. Psychrophilic yeast isolates for cold-active lipase production. Bhavan's Vivekananda College, Sanikpuri, Secunderabad. Inter. J. Sci. Pro. Res. 10: 93-97.

Fahy, A., A. S. Ball, G. Lethbridge, K. N. Timmis and McGenity, T. J. 2008. Isolation of alkali- tolerant benzene- degrading bacteria from a contaminated aquifer. Lett. Appl. Microbiol. 47(1): 60-66.

Friedmann, E. I., 1993. Antarctic Microbiology. New York: Wiley-Liss.

Gunde-Cimerman, N., S. Sonjak, P. Zalar, J. C. Frisvad, B. Diderichsen and Plemenitaš, A. 2003. Extremophilic fungi in arctic ice: a relationship between adaptation to low temperature and water activity. Phy. Chem. Earth Parts A/B/C, 28(28-32): 1273-1278.

Gupta, N., P. Rathi and Gupta, R. 2002. Simplified para-nitrophenyl palmitate assay for lipases and esterases. Anal. Biochem. 311: 98-99.

Hasan, F., A. A. Shah and Hameed, A. 2006. Industrial applications of microbial lipases. Enzy. Micro. Technol. 39, 235251.

Hatha, A. A. M., K. M. Mujeeb Rahiman, K. P. Krishnan, A. V. Saramma and Saritha, G. 2013. Characterization and bioprospecting of cold adapted yeast from water samples of Kongsfjord, Norwegian Artic. Indian J. Geo-Marine Sci. 42, 458465.

Huang, L., T. Ma, D. Li, F. L. Liang, R. L. Liu and Li, G. Q. 2008. Optimization of nutrient component for diesel oil degradation by Rhodococcus erythropolis. Marine Poll. Bull. 56(10): 1714-1718.

Jeon, J. H., J. T. Kim, Y. J. Kim, H. K. Kim, H. S. Lee, S. G. Kang, S. J. Kim and Lee, J. H. 2009. Cloning and characterization of a new cold-active lipase from a deep-sea sediment metagenome. Appl. Microbiol. Biotechnol. 81(5): 865-874.

Joseph, B., N. Shrivastava, and Ramteke, P. W. 2012. Extracellular cold-active lipase of Microbacterium luteolum isolated from Gangotri glacier, western Himalaya: Isolation, partial purification and characterization. J. Genet. Eng. Biotechnol. 10, 137-144.

Joseph, B., P. W. Ramteke and Thomas, G. 2008. Cold active microbial lipases: some hot issues and recent developments. Biotechnol. Adv. 26, 457-470. 
Kamini, N. R., T. Fujii, T. Kurosu and Iefuji, H. 2000. Production, purification and characterization of an extracellular lipase from the yeast, Cryptococcus sp. S-2. Process Biochem. 36(4): 317-324.

Lafranconi, P. G., A. Natalello, D. Ami, L. Alberghina, S. Doglia and Lotti, M. 2005. Molecular properties, mutagenesis and over expression of the lipase from Pseudomonas fragi: a case study for coldactivity. FEBS J. 272, 372.

Lee, H. K., M. J. Ahn, S. H. Kwak, W. H. Song and Jeong, B. C. 2003. Purification and characterization of cold active lipase from psychrotrophic Aeromonas sp. LPB4. J. Microbiol. 41(1): 22-27.

Maharana, A. K., and Ray, P. 2013. Isolation and screening of cold active extracellular enzymes producing psychrotrophic bacteria from soil of Jammu City. Biosci. Biotech. Res. Asia. 10(1): 267-273.

Maharana, A. K., and Ray, P. 2014a. Application of Plackett-Burman Design for improved cold temperature production of lipase by psychrotolerant Pseudomonas sp. AKM-L5. Int. J. Curr. Microbiol. App. Sci. 3(4): 269-282.

Maharana, A. K., and Ray, P. 2014b. Low temperature degradation of various substrates by psychrotolerant Fusarium spp. isolated from soil of Jammu city. J. Adv. Microbio. 1(1): 52-56.

Maharana, A. K., and Ray, P. 2014c. Screening of psychrotrophic micro-fungi for cold active extracellular enzymes isolated from Jammu city, India. J. Pure Appl. Microbio. 8(3): 2369-2375.

Maharana, A. K., and Ray, P. 2015a. Optimization and characterization of cold-active endoglucanase produced by Aspergillus terreus strain AKM-F3 grown on sugarcane bagasse. Turk. J. Biol. 39(1): 175-185.

Maharana, A. K., and Singh, S. M. 2018. A cold and organic solvent tolerant lipase produced by Antarctic strain Rhodotorula sp. Y-23. J. Basic Microbiol. 58, 1-12. https://doi.org/10.1002/jobm.201700638.
Maharana, A., and Ray, P. 2015b. A novel coldactive lipase from psychrotolerant Pseudomonas sp. AKM-L5 showed organic solvent resistant and suitable for detergent formulation. J. Mol. Catal. B Enzym. 120, 173-178.

Marcos, M. S., M. Lozada and Dionisi, H. M. 2009. Aromatic hydrocarbon degradation genes from chronically polluted subantarctic marine sediments. Lett. Appl. Microbiol. 49, 602-608.

Margesin, R., 2009. Cold-active enzymes as new tools in Biotechnology. Extremophiles-Volume II, 3: 164.

Mayilraj, S., P. Saha, K. Suresh and Saini, H. S. 2006. Ornithinimicrobium kibberense sp. nov., isolated from the Indian Himalayas. Int. J. Syst. Evol. Microbiol. 56(7): 16571661.

Moyer, C. L., and Richard, Y. M. 2007. Psychrophiles and psychrotrophs. eLS.

Muangchinda, C., S. Chavanich, V. Viyakarn, K. Watanabe, S. Imura, A. S. Vangnai and Pinyakong, O. 2014. Abundance and diversity of functional genes involved in the degradation of aromatic hydrocarbons in Antarctic soils and sediments around Syowa Station. Environ. Sci. Pollut. R. 22(6): 4725-4735.

Pham, V.H., J. Kim and Jeong, S. W. 2014. Enhanced isolation and culture of highly efficient psychrophilic oil-degrading bacteria from oil-contaminated soils in South Korea. J. Environ. Biol. 35(6): 1145-1149.

Rapp, P., and Backhaus, S. 1992. Formation of extracellular lipases by filamentous fungi, yeasts, and bacteria. Enzyme Microb. Technol. 14, 938-943.

Reddy, P. V. V., S. S. S. N. Rao, M. S. Pratibha, B. Sailaja, B. Kavya, R. R. Manorama, S. M. Singh, T. N. R. Srinivas and Shivaji, S. 2009. Bacterial diversity and bioprospecting for cold-active enzymes from culturable bacteria associated with sediment of melt water stream of Midtre Lovenbreen glacier, an Arctic glacier. Res. Microbiol. 160(8): 538-546. 
Shivaji, S., M. S. Pratibha, B. Sailaja, K. H. Kishore, A. K. Singh, Z. Begum, U. Anarasi, S. R. Prabagaran, G. S. N. Reddy and Srinivas, T. N. R. 2011. Bacterial diversity of soil in the vicinity of Pindari glacier, Himalayan mountain ranges, India, using culturable bacteria and soil $16 \mathrm{~S}$ rRNA gene clones. Extremophiles. 15(1): 1-22.

Singh, A. K., A. K. Maharana, H. Masih, Y. Kumar and Mishra, S. K. 2012b. Production, optimization and purification of bacterial cellulase by solid state bioprocessing of agro biomass. Res. J. Pharm. Biol. Chem. Sci. 3(2): 977-989.

Singh, P., S. M. Singh and Dhakephalkar, P. 2014a. Diversity, cold active enzymes and adaptation strategies of bacteria inhabiting glacier cryoconite holes of High Arctic. Extremophiles, 18(2): 229242.

Singh, P., S. M. Singh and Roy, U. 2015. Taxonomic characterization and the bio- potential of bacteria isolated from glacier ice cores in the High Arctic. J. Basic Microbiol. 56(3): 275-285.

Singh, P., S. M. Singh, M. Tsuji, G. S. Prasad and Hoshino, T. 2014b. Rhodotorula svalbardensis sp. nov., a novel yeast species isolated from cryoconite holes of
Ny-Ålesund, Arctic. Cryobiology. 68(1): 122-128.

Singh, S. M., S. K. Singh, L. S. Yadav, P. N. Singh and Ravindra, R. 2012a. Filamentous soil fungi from Ny-Ålesund, Spitsbergen, and screening for extracellular enzymes. Arctic. 45-55.

Taskin, M., M. H. Ucar, Y. Unver, A. A. Kara, M. Ozdemir and Ortucu, S. 2016. Lipase production with free and immobilized cells of cold-adapted yeast Rhodotorula glutinis HL25. Biocatal. Agric. Biotechnol. 8, 97-103.

Vaz, A. B., L. H. Rosa, M. L. Vieira, V. D. Garcia, L. R. Brandão, L. C. Teixeira, M. Moliné, D. Libkind, M. Van Broock and Rosa, C. A. 2011. The diversity, extracellular enzymatic activities and photoprotective compounds of yeasts isolated in Antarctica. Braz. J. Microbiol. 42, 937-947.

Zalar, P., and Gunde-Cimerman, N. 2014. Coldadapted yeasts In: Antarctic habitats (Eds.) P. Buzzini and R. Margesin. Springer, Berlin. Pp. 49-73.

Zeng, X., X. Xiao, P. Wang and Wang, R. 2004. Screening and characterization of psychrotrophic lipolytic bacteria from deep-sea sediments. J. Microbiol. Biotechnol. 14(5): 952-958.

\section{How to cite this article:}

Abhas Kumar Maharana and Shiv Mohan Singh. 2018. Cold Active Lipases Produced by Cryptococcus sp. Y-32 and Rhodococcus erythropolis N149 Isolated from Nella Lake, Antarctica. Int.J.Curr.Microbiol.App.Sci. 7(03): 1910-1926. doi: https://doi.org/10.20546/ijcmas.2018.703.227 